\title{
Os desenhos de Villard de Honnecourt e o processo projetivo na Idade Média
}

\author{
The drawings of Villard de Honnecourt and the projective process in the Middle Ages
}

\author{
> Flávia Massaro Fonseca \\ Universidade de São Paulo, \\ Instituto de Arquitetura e Urbanismo \\ flavia.fonseca@usp.br
}

\author{
> Simone Helena Tanoue Vizioli \\ Universidade de São Paulo, \\ Instituto de Arquitetura e Urbanismo \\ simonehtv@sc.usp.br
}

\begin{abstract}
This paper began by architectural drawings' study in the Middle Ages, among them, the drawings of the Villard de Honnecourt's sketchbook, foreman of the thirteenth century. Through these drawings we could analyzed how the construction and design process of Gothic cathedrals was developed in the construction site. This study aimed to analyze the difficulties in the construction process by reading the drawings, as well as its own richness graphic. The project presents the redesign and the analysis of the Honnecourt and Gothic cathedrals as well as the execution of reduced physical models.
\end{abstract}

Keywords: Draw; Villard de Honnecourt; Gothic Cathedrals; Representation.

\section{Introdução}

Esta pesquisa integra os trabalhos que vem sendo realizados no N.elac (Núcleo de Apoio à Pesquisa em Estudos de Linguagem em Arquitetura e Cidade) do Instituto de Arquitetura e Urbanismo da Universidade de São Paulo, grupo do qual a pesquisadora é integrante, cujo objetivo é destacar os vínculos entre os meios de representação, artísticos ou não, e a consciência crítica e propositiva de espacialidade, seja urbana ou arquitetônica.

Pretendeu-se analisar o projeto da Catedral Notre-Dame de Reims tendo como referência principal o desenho de fachada-corte de Villard de Honnecourt, mestre de obras do século XIII. Para tanto, foram utilizados alguns recursos tecnológicos atuais que auxiliaram na compreensão da obra, como o CAD, a mesa digitalizadora e a cortadora à laser.

A discussão feita neste trabalho trouxe como enfoque a arquitetura nos séculos XII e XIII, por meio da percepção e do desenho como representaçáo do processo projetivo, bem como a reflexáo sobre sua importância até os dias de hoje.

Existem diferentes maneiras de se representar um projeto de arquitetura. Observa-se nos dias de hoje, grandes mudanças nos sistemas de representação gráfica devido ao desenvolvimento de novas tecnologias e a utilização do computador, através das interfaces digitais e de programas como CAD (Computer Aided Design). Entretanto, apesar dos inúmeros benefícios proporcionados pelos sistemas digitais, deve ser levada em conta a importância do desenho analógico como processo projetivo e de representação desde a Antiguidade, já que o desenvolvimento das grandes obras arquitetônicas, nessa época, passando também pelo Renascimento, era auxiliado apenas pelos desenhos manuais.

Herdaram-se dois trabalhos da História e do desenho da Antiguidade que reuniam o conhecimento da construção das estruturas, de máquinas e da natureza: o Tratado de Vitrúvio (escrito em aproximadamente 27 a. C.), e o manuscrito de Villard de Honnecourt da Picardia, na França (escrito no século XIII) (Borges Filho, 2005).

A coletânea de desenhos de Villard de Honnecourt é a mais importante do período medieval. Nela, há o registro de procedimentos práticos para a obtenção de elementos arquitetônicos, esquemas geométricos para facilitar o desenho de figuras e até receitas para ferimentos que possivelmente ocorressem no canteiro de obras. Nos estudos de Honnecourt, defronta- se com a Geometria prática - a Geometria Fabrorum - a qual era utilizada pelo mestre de obras para resolver os problemas diários do canteiro. Os textos que acompanham os desenhos não são claros quanto à construçáo e obtenção do resultado enunciado, o que, segundo Borges Filho (2005), fortalece a ideia de transmissão oral do procedimento.

$\mathrm{Na}$ história da arquitetura, as formas a serem construídas foram grandes desafios aos mestres de obras, projetistas e arquitetos. $\mathrm{Na}$ Idade Média, muitas vezes, os desenhos bidimensionais das grandes construçôes - pontes, fortes, igrejas - eram executados no próprio canteiro de obras, no chão ou nas paredes. A edificaçáo tinha seu planejamento finalizado apenas com o término da obra, não havia um planejamento de todo o edifício de forma prévia (Sousa, 2007). Hoje ainda são utilizados, na prática da representação espacial, os desenhos de plantas, cortes e fachadas, provavelmente introduzidos 
no século XV (Rebello, Eloy e Leite, 2006). No período do Renascimento, estes desenhos contribuíam para construir edificaçóes com uma maior precisão. Através do corte detalhado, por exemplo, a construçáo da arquitetura era melhor controlada e provavelmente mais rápida, pelo menos no que se referia à organização do canteiro de obras. Apenas após o desenvolvimento do sistema de representaçáo em perspectiva através de planta e fachada relacionadas, por Brunelleschi, esse tipo de desenho, em projeção (principalmente o corte) teve seu uso difundido no sul da Europa e na Itália.

\section{Arquitetura e catedrais góticas}

A arquitetura Gótica surgiu como um estilo no final da primeira metade do século XII, em Île-de-France, tendo a catedral de Sens $(1130$ - 1162) e a abadia de Saint-Denis (c. 1130 - 1140 e 1140 1144) como os dois exemplos mais proeminentes desta fase inicial de desenvolvimento. (Grodecki, 1978).

Dentre esses edifícios, a abadia de Saint-Denis exerce papel de grande monumento da Idade Média europeia, sendo designada como "a mãe das igrejas francesas" (Rabelo, 2005). A igreja sofreu reformas significativas realizadas entre 1137 e 1144, promovidas pelo abade Suger. Suas modificaçóes na estrutura da igreja e o desenvolvimento de uma nova concepção do espaço, tonaram a abadia distinta em relação às outras construçôes românicas do mesmo período. Segundo Rabelo (2005), ela é vista pelos estudiosos da arte medieval como um protótipo da arquitetura gótica, que se espalhará pela Europa nos séculos seguintes.

As bases da arquitetura gótica se estabeleceram nas Universidades, seguindo um severo postulado escolástico - Deus como unidade Suprema e Matemática. Abrangendo também as áreas da pintura e da escultura, o gótico, com suas formas verticais, a pureza das linhas e a ornamentação na arquitetura resultavam numa renovação das formas e técnicas, com o objetivo de expressar a harmonia divina (Lyra, 2008).

Pode-se dizer que o estilo gótico e o seu sistema estrutual, foi uma importante forma de pensar a estrutura do edifício. Não há, nessa época, registros gráficos dos projetos de arquitetura (até o Renascimento os desenhos arquitetônicos não eram comuns). Nesse período, havia o indício de uma separação, em termos de planejamento, da arquitetura e da estrutura, mas não existiam projetos de fato, separados. $\mathrm{O}$ arquiteto ficava no canteiro de obras, e a concepção do espaço era feita ali mesmo, de forma prática, juntamente com a execução dos detalhes durante a obra (Sousa, 2007).

Duas das inovaçôes mais importantes para a construção gótica, o arco ogival (responsável pela elevação vertical do edifício) e a abóbada cruzada (permite a cobertura de espaços quadrados, curvos ou irregulares), permitiram, entre outros fatores, a distribuição de luz no espaço, a desmaterialização de paredes e a elevação da catedral, características gerais de diferenciação da construção gótica (Lyra, 2008).

A mudança veio com a substituição dos arcos de meia circunferência pelos arcos ogivais, que diminuíam a pressão lateral exercida, permitindo uma maior articulação de forças. Dessa forma, através das nervuras estruturais desses arcos, as forças eram distribuídas para os pilares de sustentação e para os contrafortes no exterior podendo, assim, serem utilizados materiais mais leves tanto para a abóboda como para as bases de sustentação (Lyra, 2008). Assim, pode-se dizer que os arcos ogivais permitiram a utilização de colunas mais esbeltas sem comprometer a estabilidade da estrutura. As paredes, que por sua vez, perdem a sua função estrutural, dão lugar aos grandes vitrais que proporcionam a distribuição de luz no interior do edifício.

\section{Notre-Dame de Reims}

A catedral de Notre-Dame de Reims localiza-se na regiāo de Champagne, na França. Foi construída no século XIII, possuindo uma história bastante complexa, pois a obra foi interrompida em 1223, com o coro ainda não abobadado, até 1241. Ainda assim, até o século XIV, as seçóes superiores das torres continuavam em construção, sabe-se também que o projeto foi dirigido por quatro arquitetos em sucessão.

Segundo Grodecki (1978), a catedral é uma imitação da catedral de Chartres, onde seus planos incluem um transepto ladeado por corredores laterais que são dobrados ao longo do coro. Seu espaço interno também é um exemplo de Chartres, possuindo o mesmo peso, força plástica, e abundância de filtragem da luz através de janelas duplas no clerestório, assim como nos corredores laterais e capelas. Entretanto, Reims se difere dela em alguns aspectos, como uma passagem na parede que corre ao longo da base das janelas das capelas e corredores laterais (Grodecki, 1978).

$\mathrm{Na}$ parte exterior, os arcobotantes e pilares, duplamente distribuídos, do cais até a parede da nave, com uma fileira dupla no coro, estão integrados no estilo e forma geral da estrutura. Além disso, os pináculos ecoavam a forma das torres e as estátuas de anjos, o que aponta novamente para a imaginação incomum com que o arquiteto de Reims transformou o modelo original (Grodecki, 1978).

\section{Villard de Honnecourt}

Mestre de obras da Idade Média, Villard de Honnecourt, da Picardia no Ocidente europeu, deixou um manuscrito datado do século XIII, cerca de 1250 após outro trabalho monumental, o de Vitrúvio, escrito na Antiguidade (aproximadamente em 27 a. C.).

Presente em seus desenhos, a Geometria Prática - Geometria Fabrorum - aparece como uma ferramenta para resolver os problemas diários no canteiro de obras, estudo que revela como fonte os excertos de Os Elementos de Euclides (Borges Filho, 2005). Segundo Minto (2009), o arquiteto sempre esteve ligado a esta prática de construir, como nessa época, em que se formava e se aprendia no próprio canteiro de obras. A comprovação das capacidades dessa figura importante que era o mestre de obras, e então arquiteto, era feita através da constatação do que era capaz de produzir no canteiro, ou seja, se ele o que ele projetava e construía era, de fato, bom (Minto, 2009).

Os cadernos de Honnecourt possuem a característica de um caderno de anotaçóes, contendo croquis rápidos, croquis mais elaborados, ideias, invençóes e até receitas utilizadas pelo próprio Villard. No texto de abertura do trabalho pode-se verificar que o autor dedica a obra aos seus sucessores, que ao lerem, encontrarão 
conselhos sobre alvenaria e carpintaria, ajuda para desenhar figuras de acordo com a geometria.

Os desenhos técnicos presentes nos cadernos dividem-se em procedimentos práticos do canteiro, processos de traçado ou corte de pedras e que parecem ser das experiências do próprio autor (Borges Filho, 2005).

\section{Metodologia}

A pesquisa foi dividida em três momentos: o primeiro, referente a construção de repertório (revisão bibliográfica, levantamento de dados, quadros conceituais); o segundo tratou das investigaçóes experimentais (confecção dos desenhos em laboratório); e um terceiro momento de reflexão teórica.

Este artigo traz com maior destaque o segundo momento da pesquisa, que abrange a experimentação prática, que constituiu-se de:

a. Interpretação e redesenho do corte e da fachada: impressão do desenho e elaboração dos redesenhos a mão livre.

b. Redesenhos do corte a mão utilizando instrumentos (régua e esquadro) em papel manteiga.

c. No decorrer deste processo houve a necessidade de separar o desenho em camadas para a confecçáo da etapa

d. Nesta etapa foi utilizada a mesa digitalizadora, que possibilitou o desenho a mão livre digital juntamente com o software Adobe Photoshop. Este recurso foi necessário para a identificaçáo de cada camada da catedral, para posterior corte a laser.

e. Desenhos em CAD: Após as análises e redenhos feitos nos itens a, b e c, foram elaborados os desenhos finais em camadas utilizando software como Archicad e Autocad. Esses desenhos são precisos e limpos, e foram exportados para o software da cortadora a laser, chamado Laserwork.

f. Processo de corte a laser: O software Laserwork recebe desenhos em formatos CAD, e 'imprime' os desenhos, nesse caso, em madeira mdf, utilizando o laser.

O terceiro momento da pesquisa consistiu na análise comparativa entre os três desenhos cortados a laser: desenho total da fachada; desenho total do corte e desenho ao modo de Villard de Honnecourt - representaçáo do corte junto com a fachada no mesmo desenho.

Dentre as imagens encontradas, utilizou-se como principal referência para o produto final deste trabalho a figura onde o corte-fachada se apresentam no mesmo desenho feito por Villard de Honnecourt. Esta e outras imagens do mestre de obras foram encontradas em seu manuscrito no site da Biblioteca Nacional da França e no trabalho de Borges Filho (2005). Imagem esta que apresenta uma inovação na maneira de representar a arquitetura e também a busca pelo entendimento de projeto elaborado por Honnecourt na Idade Média.

Para que fosse possível a realização dos produtos finais foi imprescindível a busca por imagens de peças gráficas da catedral, como planta, cortes e fachadas, e até mesmo fotografias, para que pudessem serem feitos os redesenhos e, ao final do processo, a execução da representação bidimensional com profundidade (Utilizou-se este termo pois o produto final é um desenho que adquiriu profundidade com a adição de camadas e, dessa forma, ele não é classificado nem como desenho e nem como maquete física, mas aproxima-se de ambos), pela pesquisadora.

\section{Resultados}

Como produtos finais da pesquisa, obteve-se entáo três desenhos cortados a laser: desenho total da fachada; desenho total do corte e desenho ao modo de Villard de Honnecourt - representação do corte junto com a fachada no mesmo desenho. A escolha pela realização dos desenhos inteiros do corte e da fachada buscou uma apropriação de forma mais didática do objeto de estudo, resultando numa familiarização e facilidade no entendimento, já que para realizar o processo em camadas, foi preciso entender anteriormente, a catedral como um todo.

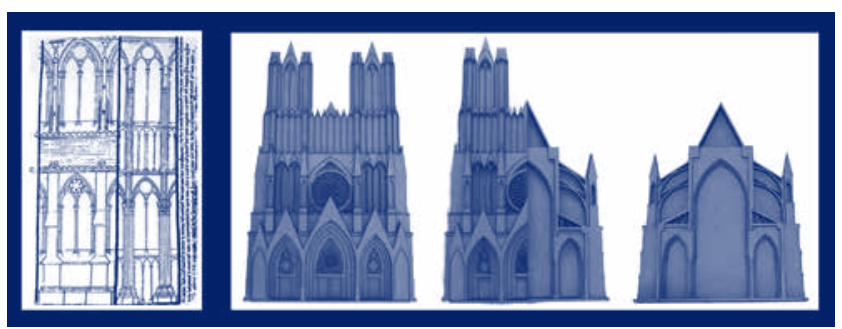

(a)

(b)

Figura 1: Desenho de fachada/corte de Villard de Honnecourt (a) (Fonte: Borges Filho, 2005) e desenhos com profundidade em madeira cortada a laser, produzidos pela pesquisadora (b).

Estes três desenhos, sendo acrescentados com a profundidade das camadas, dá indícios de uma representação em perspectiva, e traz consigo o processo de hibridização. Ou seja, utiliza duas formas de representar arquitetura, mas que, ao mesmo tempo, aborda um novo objeto, fazendo a ligaçáo entre o desenho e o modelo, ferramentas tấo importantes para o processo de projeto e representação da arquitetura, como foi abordado ao longo deste trabalho.

Foi elaborada também, pela pesquisadora, uma enquete com 20 alunos do $3^{\circ}$ ano/2014 do Instituto de Arquitetura e Urbanismo da Usp, acerca dos produtos obtidos. A enquete contou com uma questâo sobre o entendimento da Catedral Reims, expondo aos alunos o desenho do corte-fachada de Villard de Honnecourt e o desenho com profundidade elaborado pela pesquisadora. Dessa forma, ficou comprovado que a releitura da cathedral utilizando ferramentas de representação que vão desde o desenho feito à mão, até a tecnologias de alta precisáo como a cortadora a laser, auxiliam na compreensão da obra.

\section{Conclusões}

Pode-se dizer, dessa forma, que este estudo realizado foi importante por trazer uma investigação sobre a forma de se representar a arquitetura no século XIII, época em que a construção de um edifício não utilizava desenhos feitos com ferramentas de alta precisão, como hoje. A elaboraçáo de redenhos e modelos da catedral Notre-Dame de Reims possibilitou a compreensão de como a obra 
e a sua representação interagiam naquele período. Além disso, foi importante também por trazer à luz as possíveis dificuldades encontradas nos canteiros de obra na feitoria das obras por meio da leitura desses desenhos, bem como a riqueza gráfica ali presente, principalmente ao ressaltar a inovaçáo de representação conjunta do corte com a fachada. É importante, neste momento, ressaltar o papel da representação feita pelo mestre de obras ainda no século XIII, que sistematizou e articulou representaçôes externa e interna de um edifício no mesmo desenho. Representação esta que foi retomada apenas três séculos depois, por Palladio, no período do Renascimento.

Diferentemente da Idade Média, nos dias atuais os projetos são assessorados por novos recursos tecnológicos, tanto na área dos desenhos, como na área dos modelos. A utilização da mesa digitalizadora cintiq proporcionou também organização o desenvolvimento de um desenho melhor detalhado. Soma-se a isto a contribuição da cortadora a laser, que completou este processo com impressôes de alta definição, o que não seria possível sem a mesma. Dessa forma, pode-se inferir que a utilização de ferramentas de alta precisão, combinadas com a análise de desenhos e redesenhos feitos à mão livre, tornou possível náo apenas um maior detalhamento sobre o objeto de pesquisa, mas permitiu também a construçáo de um novo olhar e o entendimento sobre o que está sendo produzido, bem como ressaltar a importância deste estudo e sistematização de formas de representação para a arquitetura.

\section{Agradecimentos}

Agradeço à Pró-Reitoria de Pesquisa da Universidade de São Paulo, IAU.USP, aos grupos de pesquisa N.ELAC (Núcleo de Apoio à Pesquisa em Estudos de Linguagem em Arquitetura e Cidade) e Nomads (Núcleo de Estudos de Habitares Interativos), e à FAPESP, pelo apoio ao desenvolvimento deste trabalho.

\section{Referências}

Borges Filho, F. (2005). O Desenho e o Canteiro no Renascimento Medieval (séculos XII e XIII): Indicativos da formação dos arquitetos mestres construtores. São Paulo: FAUUSP.

Grodecki, L. (1978) Gothic Architecture. Milão: Electa Editrice.

Lyra, W. L. D. (2008). Intercomunicação entre matemática - ciência - arte: um estudo sobre as implicaçóes das geometrias na produção artística desde o gótico até o surrealismo. São Paulo: USP.

Minto, F. C. N. (2009). A experimentação prática construtiva na formação do arquiteto. São Paulo: FAUUSP.

Rabelo, M. M. (2005). A Abade Suger, a Igreja de Saint-Denis e os primórdios da arquitetura gótica na Îlle-De-France do século XII. Campinas: UNICAMP.

Rebello, Y.; Eloy, E.; Leite, M. A. D. (2006). A métrica da forma. In: Arquitetura e Urbanismo.

Sousa, M. G. de. (2007). Histórico da relação e comunicação gráfica entre projeto de arquitetura e o projeto de estrutura. Curitiba. 